\title{
Do Estado Corporativo à Liberdade Sindical*
}

\author{
Wagner D. Giglio \\ Professor Adjunto de Direito do Trabalho, \\ da Faculdade de Direito da Universidade de \\ São Paulo
}

SUMÁRIO: 1. "Estado Novo" - 2. Estrutura sindical - 3. Liberdade sindical - 4. Conclusōes.

\section{1. "Estado Novo"}

Derrotado em eleições fraudulentas, o candidato Getúlio Vargas assumiu a Presidência da República através de um movimento armado que durou poucas semanas, em 1930.

O governo provisório tinha os propósitos de eliminar as fraudes eleitorais, então comuns e freqüentes, alterar as estruturas políticas e incentivar a legislação trabalhista. O Direito do Trabalho brasileiro nasceu, praticamente, com as leis sancionadas entre 1930 e 1932 pelo Governo de Vargas.

Em 1934 adotou-se nova Constituição, de caráter socialista, que previa, entre outras inovações, a existência de parlamentares escolhidos pelas entidades de classe, a liberdade e o pluralismo sindicais.

Seguiu-se um período de conturbações sociais que se encerrou com o golpe de Estado das próprias forças políticas dirigentes, lideradas pelo mesmo Getúlio Vargas, em 10 de novembro de 1937, quando foi outorgada nova Carta Constitucional, inspirada, do ponto de vista econômico-social, na Carta del Lavoro do regime fascista italiano, e instaurado o que se passou a denominar o "Estado Novo"

Foram fechadas as duas casas do Congresso Nacional, passando o Poder Executivo a exercer suas funções, legislando através de decretos-leis. Estabeleceu-se a censura dos veículos de comunicação (jornais, revistas e rádio-emissoras), e ficaram proibidas as atividades políticas. Eliminadas as eleições, os dirigentes eram nomeados diretamente pelo governo central ou através de seus prepostos, os governadores dos Estados-membros e prefeitos dos Municípios. A estrutura federativa do Brasil foi sendo paulatinamente enfraquecida, com o fortalecimento crescente do Poder Executivo central.

* Trabalho apresentado no Seminário sobre o tema, realizado em Roma, nos dias 14 e 15 de outubro de 1983. 
Foi durante o periodo de vigência da Carta Constitucional de 1937 (até 1945) que se instituiu o salário mínimo (1940) e a Justiça do Trabalho (1941), além de haver sido promulgada a Consolidação das Leis do Trabalho (1943). Essa Constituição proibiu a greve, qualificando-a de recurso anti-social, e eliminou totalmente a liberdade sindical.

Foi diante desse cenário que surgiu nossa primeira lei de organização sindical, elaborada pelo mais sociólogo do que jurista Oliveira Viana, assessor jurídico do Ministério do Trabalho.

A estrutura sindical instaurada por essa primeira lei, de 1939, permanece em vigor, em suas linhas básicas, até os dias de hoje.

\section{Estrutura Sindical}

Para fins de organização sindical tomou-se por célula unitária a "categoria profíssional", composta pelos trabalhadores que exercem a "mesma atividade econômica" ou "atividades econômicas similares ou conexas" (CLT, art. 511, $\S 2^{\circ}$ ), dentro de uma predeterminada área geográfica.

As profissões e atividades similares e conexas foram arroladas num quadro estipulado em lei, revisto periodicamente, e que estabelece uma correspondência com as categorias econômicas, ou seja, os empregadores que exploram atividades idênticas, similares ou conexas (CLT, art. 511, § 1\%).

Tanto as categorias profissionais como as correspondentes categorias econômicas podem formar "associações para fins de estudo, defesa e coordenação dos seus interesses" (CLT, art. 511).

As associações são entidades de direito privado, e podem livremente ser constituídas, muito embora devam ser registradas nas Delegacias Regionais do Trabalho, órgãos do Poder Executivo Federal; mas não representam os interesses gerais da categoria profissional ou econômica, e sim apenas os interesses individuais de seus associados (CLT, art. 558 e $\$ 1^{\circ}$ ).

Somente as associações podem almejar a condição de sindicato, que lhes é reconhecida pelo Ministério do Trabalho (CLT, art. 512), desde que reúnam, no mínimo, um terço $(1 / 3)$ dos integrantes da categoria profissional (para os sindicatos de trabalhadores) ou das empresas integrantes da categoria econômica (para os sindicatos dos empregadores), dentro de uma delimitada extensão territorial prefixada pelo governo (CLT, art. 515).

Os sindicatos reconhecidos têm, entre outras, as seguintes prerrogativas: representar os interesses gerais da respectiva categoria (profissional ou econômica, conforme o caso), celebrar contratos coletivos, propor dissídios coletivos na Justiça do Trabalho e impor contribuições a todos os integrantes da categoria, associados ou nãoassociados (CLT, art. 513). E são deveres dos sindicatos, entre 
outros, manter serviço de assistência judiciária e colaborar com os poderes públicos (CLT, art. 514).

Tais caracteristicas imprimem aos sindicatos a aparência de entidades de direito público, muito embora essa classificação ainda seja discutida pelos doutrinadores.

Dentro dos limites territoriais de cada Estado-membro do país, cinco ou mais sindicatos podem se unir e formar uma Federação, obedecido o enquadramento legal das profissões ou atividades econômicas agrupadas em setores, por lei. As Federações também dependem do reconhecimento do Ministério do Trabalho para terem existência legal, e exercem funções de coordenação dos interesses dos sindicatos nela integrados (CLT, art. 534).

Finalmente, o art. 535 da Consolidação prevê, rigidamente, a constituição e atẻ e denominação das Confederações, órgãos sindicais de cúpula, que devem ser reconhecidos por decreto do Presidente da República:

Art. 535 - "As confederações organizar-se-ão com o mínimo de três federações e terão sede na Capital da República".

$\S 1$ — - "As confederações formadas por federações de sindicatos de empregadores denominar-se-ão: Confederação Nacional da Indústria, Confederação Nacional do Comércio, Confederação Nacional de Transportes Marítimos, Fluviais e Aéreos, Confederação Nacional de Transportes Terrestres, Confederação Nacional de Comunicações e Publicidade, Confederação Nacional das Empresas de Crédito e Confederação Nacional de Educação e Cultura."

$\S 2$ - "As confederações formadas por federações de sindicatos de empregados terão a denominação de Confederação Nacional dos Trabalhadores na Indústria, Confederação Nacional dos Trabalhadores no Comércio, Confederação Nacional dos Trabalhadores em Transportes Marítimos, Fluviais e Aéreos, Confederação Nacional dos Trabalhadores em Transportes Terrestres, Confederação Nacional dos Trabalhadores em Comunicações e Publicidade, Confederação Nacional dos Trabalhadores em Empresas de Crédito e Confederacão Nacional dos Trabalhadores em Estabelecimentos de Educação e Cultura."

$\S 3^{\circ}$ - "Denominar-se-á Confederação Nacional das Profissões Liberais a reunião das respectivas federações,"

$\S 4^{\circ}-$ "As associações sindicais de grau superior da Agricultura e Pecuária serão organizadas na conformidade do que dispuser a lei que regular a sindicalização dessas atividades ou profissões."

\section{Liberdade Sindical}

Os estreitos moldes legais estabelecem uma verdadeira armadura medieval a tolher os movimentos das entidades sindicais. 
Somente as associações profissionais ou econômicas gozam de alguma liberdade. Os sindicatos, assim como as federações e confederações, dependem do governo até para serem constituídos, e a lei ainda regula, extensamente, como devem esses órgãos ser administrados, o processo de eleição de sua diretoria, a gestão financeira, os direitos e deveres dos associados, etc.

Dentro de cada base territorial prefixada só poderá ser constituído um sindicato e uma federação para cada categoria, num regime de absoluta unidade sindical. São expressamente proibidos quaisquer vínculos das entidades sindicais com organismos internacionais, salvo autorização especial do governo.

Muito embora haja incentivos legais para os associados, o ingresso no sindicato é livre, assim como o desligamento dele por quem quiser deixar de ser sócio.

Segundo os doutrinadores, porém, o que mais afeta a liberdade sindical são as penalidades a que estão sujeitos seus órgãos. Conforme a gravidade da infração - e às vezes por mal disfarçados motivos políticos - o governo pode punir as entidades sindicais com multa, suspensão ou destituição de dirigentes, até com "fechamento de sindicato, federação ou confederação" e "cassação da carta de reconhecimento" da entidade (CLT, art. 553)

Essa intervenção do governo na vida interna do sindicato, com medidas tão radicais como a destituição de seus dirigentes e a eliminação da entidade, tem sido objeto das mais acerbas críticas, tanto dos doutrinadores brasileiros como de entidades internacionais, como a Organização Internacional do Trabalho.

Infelizmente, destituições de diretorias de sindicatos e outras intervenções têm ocorrido com certa freqüência, até recentemente, neste mesmo ano de 1983.

Outro fator que prejudica a autonomia dos sindicatos é a existência da contribuição sindical, eufemismo com que agora se denomina o antigo "imposto sindical". Trata-se de um desconto, feito uma vez por ano, correspondente ao valor de um dia de salário de cada um dos integrantes da categoria profissional, ainda que não seja filiado ao sindicato, destinado a subvencionar as entidades de classe. Estas se acomodaram com tal auxílio, e hoje a maior parte dos sindicatos não poderia sobreviver sem essa contribuição.

São bem poucos os sindicatos que reúnem um número representativo de associados. A maioria não conta, entre seus membros contribuintes, nem mesmo com vinte por cento dos integrantes da categoria profissional. Assim, dependem, para cumprir sua missão, da ajuda monetária resultante da contribuição sindical.

Ora, como é o governo que distribui essa verba, exerce uma pressão indireta e um controle velado, sutil mas muito eficiente, das ati- 
vidades sindicais, pois pode negar o pagamento da contribuição, e assim dificultar a vida dos sindicatos.

Em sintese, a liberdade e a autonomia sindical constituem hoje, entre nós, uma meta a ser alcançada.

\section{Conclusões}

Uma visão geral do tema levaria à conclusão de que o Brasil pouco evoluiu no sentido de atingir o estágio de liberdade sindical. Apesar de o Estado atual não ser corporativo, a estrutura sindical ainda é corporativista.

De fato, as reformas da legislação sindical foram superficiais e não alteraram sua essência. O fenômeno mais relevante da vida sindical brasileira é exatamente essa sobrevivência, por mais de quarenta anos, de uma organização sindical corporativa.

Os militares, num golpe de Estado, derrubaram a ditadura de Getúlio Vargas e puseram fim à experiência fascista do "Estado Novo", em 1945. Ao final, os militares brasileiros haviam participado da II Grande Guerra lutando contra as forças nazi-fascistas, e seria incoerente que mantivessem, em seu próprio país, um regime semelhante àqueles contra os quais haviam lutado.

O Brasil se redemocratizou, convocando eleições livres, para eleger uma assembléia constituinte que aprovou, em 1946, nova Carta Magna, de caráter social-democrático, que vigorou até 1964 . Nesse ano, novo golpe de militares destituiu o Governo de João Goulart e o substituiu por dirigentes militares que vêm se sucedendo na Presidência da República até o presente.

Apesar dessas profundas alterações políticas, não houve modificação de nossa estrutura sindical, que permaneceu substancialmente a mesma implantada em 1939, durante o "Estado Novo".

Não existem estudos específicos sobre essa curiosa estagnação do sindicalismo brasileiro. Assim sendo, qualquer tentativa de explicação desse fenômeno corre o risco de ser taxada de especulativa.

Nada obstante, parece-nos que haveria boas razões para pesquisar as relaçōes entre a distribuição populacional e a falta de vida associativa mais intensa, pois as longas distâncias e a ausência de grandes concentrações populacionais dificultavam a formação de sindicatos fortes. A explosão demográfica de S. Paulo, Rio de Janeiro e poucos outros grandes centros data dos últimos vinte anos, época em que vivemos sob regime políticu repressivo das atividades sindicais.

Além disso, é sabido que o sindicalismo se desenvolve principalmente nos centros industriais, e o tardio desenvolvimento da indústria brasileira, que só tomou impulso progressista a partir de meados deste século, explicaria a inatividade do sindicalismo anterior. 
Um outro aspecto mereceria ser melhor explorado, a nosso ver: a formação cultural e psicológica de nossos líderes sindicais, acostumados a tudo receber do governo paternalista e inabituados, por isso, de lutar para obter benefícios. Esse imobilismo, essa acomodação do sindicato seria um fator importante na conservação da estrutura corporativista.

Finalmente, o bom funcionamento da Justiça do Trabalho esvazia as reinvidicações dos sindicatos, pois o trabalhador que tem atendido ali seus direitos não se inclina a buscar o apoio de sua entidade de classe, e o julgamento rápido dos conflitos coletivos subtrai significado aos movimentos grevistas.

Em conclusão, é possivel que a situação sócio-econômica do país não tenha propiciado o desenvolvimento de uma atividade sindical autêntica. Em decorrência, as entidades sindicais teriam permanecido acomodadas numa estrutura antiga, até recentemente, por falta de interesse em modificá-la.

Ultimamente, entretanto, a crise econômica, especialmente os fenômenos da inflação e do desemprego, vem oferecendo caldo de cultura ao desenvolvimento de impasses, litígios e traumas sociais virulentos, antes desconhecidos entre nós.

Sentindo-se desprotegido pelo Poder Executivo, incapaz de conter a crise, o trabalhador brasileiro começa, agora, a buscar, ele mesmo, a solução para suas dificuldades. Vivemos, atualmente, um período de interesse pelo sindicato, sua atuação e o encontro de fórmulas novas, autocompositivas, de solução dos conflitos. Ganham impulso as negociações coletivas. Multiplicam-se as greves, mesmo diante de legislação rígida, que as coíbe. Aprimoram-se mecanismos novos, no seio das grandes empresas, para dar solução às questões trabalhistas.

Em síntese, ganha a atividade sindical, em época tão tardia, a autenticidade que lhe faltava, e a sociedade vem forçando a alteração dos vetustos moldes legislativos, flagrantemente inadequados para enfrentar a realidade atual.

De São Paulo para Roma, primavera de 1983 